\title{
Human Factors in Person-Technology Relations in Business Decision Making
}

\author{
Rimvydas Skyrius \\ University of Vilnius, Vilnius, Lithuania
}

rimvydas.skyrius@ef.vu.tt

\begin{abstract}
The goal of this paper is to produce an evaluation of IT-based support of human decision capabilities, as seen by the decision makers themselves. Recent research efforts, conducted in communication with actual decision makers in business and public administration, have been directed at the evaluation of potential of information technologies (IT) in supporting high-level information activities and creation of new knowledge for the participants. Author's research experience shows that, apart from preference for simple support tools and techniques, there is a preference for tools and techniques that hold their efficiency over time in related situations, and are oriented towards more stimulation than automation. Also, a hypothesis is made that decision makers prefer more variety and flexibility in information sources than in decision models and other forms of "frozen knowledge".
\end{abstract}

\section{Introduction}

Since the early days of decision support systems (DSS) and technologies, the principal emphasis has been made on the side of supporting the decision mechanics rather than supporting the deciding person or entity. Designers often have ignored the human and organizational element, and concentrated on the technical implementation of the hardware/software mix (Hutchinson, 2000). Every next wave of technology brings its own expectations and surrounding hype; the field of decision support is no exception: on one hand, the need for reliable decision-making clues stays permanently; and, on the other hand, substantial development supply of decision support tools does not seem to play in exact tune with the above need. Some frustration in DS technologies and systems has been taking place (Davenport, 1997, Raggad, 1997) as a product of missing the target of user's needs.

Meanwhile, numbers of case studies and publications have shown benefits in separate cases, thus leading to the idea of finding out with the users themselves. Considerable recent research has been concentrating on the support of the person-technology relation in decision making. A number of works have been emphasizing that business decision making environment is a unity of decision makers' experience, beliefs and perceptions on one side, and decision support tools and techniques - on the other side. Previous research had shown that users often prefer simple tools and techniques for decision support (Skyrius, 2001). On the other hand, any tools and techniques that provide high-value support functions, e.g. stimulate intuition and creativity, are and would be welcome.

Material published as part of these proceedings, either on-line or in print, is copyrighted by Informing Science. Permission to make digital or paper copy of part or all of these works for personal or classroom use is granted without fee provided that the copies are not made or distributed for profit or commercial advantage AND that copies 1) bear this notice in full and 2) give the full citation on the first page. It is permissible to abstract these works so long as credit is given. To copy in all other cases or to republish or to post on a server or to redistribute to lists requires specific permission from the publisher at Publister@intormingsclence.org
Managerial decision making is usually characterized by a need to develop a decision with incomplete information and pressing deadlines. Existing level of problem knowledge and problem-solving knowledge, together with available support mechanisms including IT, is then put to work and tested against current problems, the by-product of such 
testing being new experience and knowledge for decision participants. Decision support is a knowledge-intensive activity, and efficient use of existing knowledge as well as creation of new knowledge are essential to decision makers' problem-solving capabilities.

To gain a better insight into currently used and preferred decision support mechanisms, use and efficiency of support tools - IT in the first place, are discussed on the basis of surveys and interviews, conducted among decision makers in Lithuania in 1999-2001. The most recent research has been conducted on the basis of personal interviews in order to gain more open responses than a questionnaire can provide. The author has been investigating this area in the form of surveys since 1995, both in Lithuania and in the USA, and the results allow us to suppose that questionnaires, while good at collecting simple answers and hard data, need to be combined with personal interviews to provide insight beyond these simple answers. Consequently, the aim of this paper is: to gain more insight into the users' attitudes towards computerbased decision support and actual utilization of IT resources for this role by combining face-to-face interviews and existing research on the subject.

\section{Existing Research}

A substantial amount of recent work in the field of management decision making and IT-based support has been related to such aspects as intuition, creativity, knowledge creation and utilization, information search and navigation functions. This work, in my opinion, can be related to a more general area of recent information systems research interest, namely, human-centristic or user-centristic IS research and development (Hutchinson, 2000; Ivanov, 2001; Malhotra 2000). Some researchers in the area are stating that at the forefront of all design improvements should be the goal of better leveraging and augmenting of natural human capabilities (Workshop on Information ..., 1999). Among work, dedicated to research user features in managerial decision making, we can note decision typology, presented by Basi (Basi, 1998), which specifies four principal types of decisions by the degree of certainty of their causes and outcomes:

- Computational decision - certainty about causation and outcome preferences

- Judgmental decision - outcome preferences are clear, but cause and effect relationships are uncertain

- Compromise decision - there is certainty about cause and effect relationships but uncertainty about outcome preferences

- Inspirational decision - uncertainty about both; in this situation, a philosophical mind able to make informed, intuitive decisions based on historical data entwined with future perspective is necessary.

Basi also states that, because of the lack of the accurate data, decisions are likely to be inspirational (intuitive) or judgmental, born out of seasoned background and informed perspectives. Such features are typical to most of the decisions that are clients of DSS.

In managers' subjective approaches to decision making, Andersen (Andersen, 2000) points out four basic psychological functions: sensing - function that tells us something exists; intuition - reveals the possibilities which may exist in what has been perceived; thinking - tells us what this something is; feeling tells us how to relate to what we have perceived based on our own subjective value system. The same source also states that intuition and thinking are most important in the creative and selective phases of decision making - alternative generation, analysis of outcomes and decision selection.

Sauter (Sauter, 1999) points out that managerial intuition is a key personal feature in decision making, and, while being far from simple to define more exactly, intuition lends itself to being indirectly supported 
by such features like tracking of past decisions, capturing ideas and accumulation of experiences with their close and distant contexts. It has to be noted here that the widely proposed accumulation of best practices, which is often presented in the context of knowledge management issues, should be regarded critically - some earlier responses have indicated that it can seed stereotypes and stifle creativity. Galliers and Newell (Galliers, \& Newell, 2000) are stating that it is the contestability of knowledge and truth that leads to innovation and creativity.

More findings on the use of intuition in managerial decision making are presented in Bennett's paper (Bennett, 1998), where he points out that top managers are better in use of intuition, the reason for this being the ability to concentrate on 'big picture' and resist to concentration on details. When environment shifts happen, managers display an amazing amount of intuition about the unforeseen. The same work describes the dynamics of intuition in decision groups: insiders provide data and efficiency; outsiders provide perspective; presented data provokes intuition; intuitive thoughts call for more data and so on, deepening and widening the understanding of the problem in the process.

Summing up the more important points in available research from the perspective of this paper:

- decision making process uses a unity of hard data support and decision makers' experience, knowledge and intuition;

- intuition is of vital importance in deciding stages where creativity is required - i.e. generating alternatives;

- combination of presented decision support data and intuition boosts understanding of a problem and stimulates decision development.

\section{Problem Area Structuring}

In this work, an attempt is made to determine the preferred level of decision support provided by IT. The findings have been directed at the contents of real decision-making processes and actions undertaken there by decision-makers.

The development of a decision in terms of acquiring a desired level of understanding of the problem to be solved and its possible solutions has been described in a variety of work, using models such as 'garbage bin' (Browne, 1993; Saunders, \& Jones, 1990) and others. To my opinion, there is a cognitive gap to be filled between initial addressing of the problem and its final solution; the size of this gap determines the time and effort required to develop a sufficient solution. In structured problems this time amounts to the time it takes to perform the necessary procedures in developing a decision through a predefined path; in some cases this time might be nearing zero. In semi-structured and unstructured problems, which often spring up unexpectedly, the time to develop a decision is under deficit, and at the same time it is hard to reduce or even define its duration. A generic dependency between decision development and support procedures is shown in the Figure 1.

Initial understanding of the problem includes (but not necessarily all of the below):

- problem definition,

- goals,

- assumptions,

- participants,

- stakeholders and forces in action, 
- direct facts,

- background,

- analogies and related cases,

- ethic and social background.

Processing encompasses:

- location of principal and additional information sources,

- simple filtering and queries,

- ordering/sorting the inflow of information,

- data cleaning,

- data combining,

- development and use of models, etc.

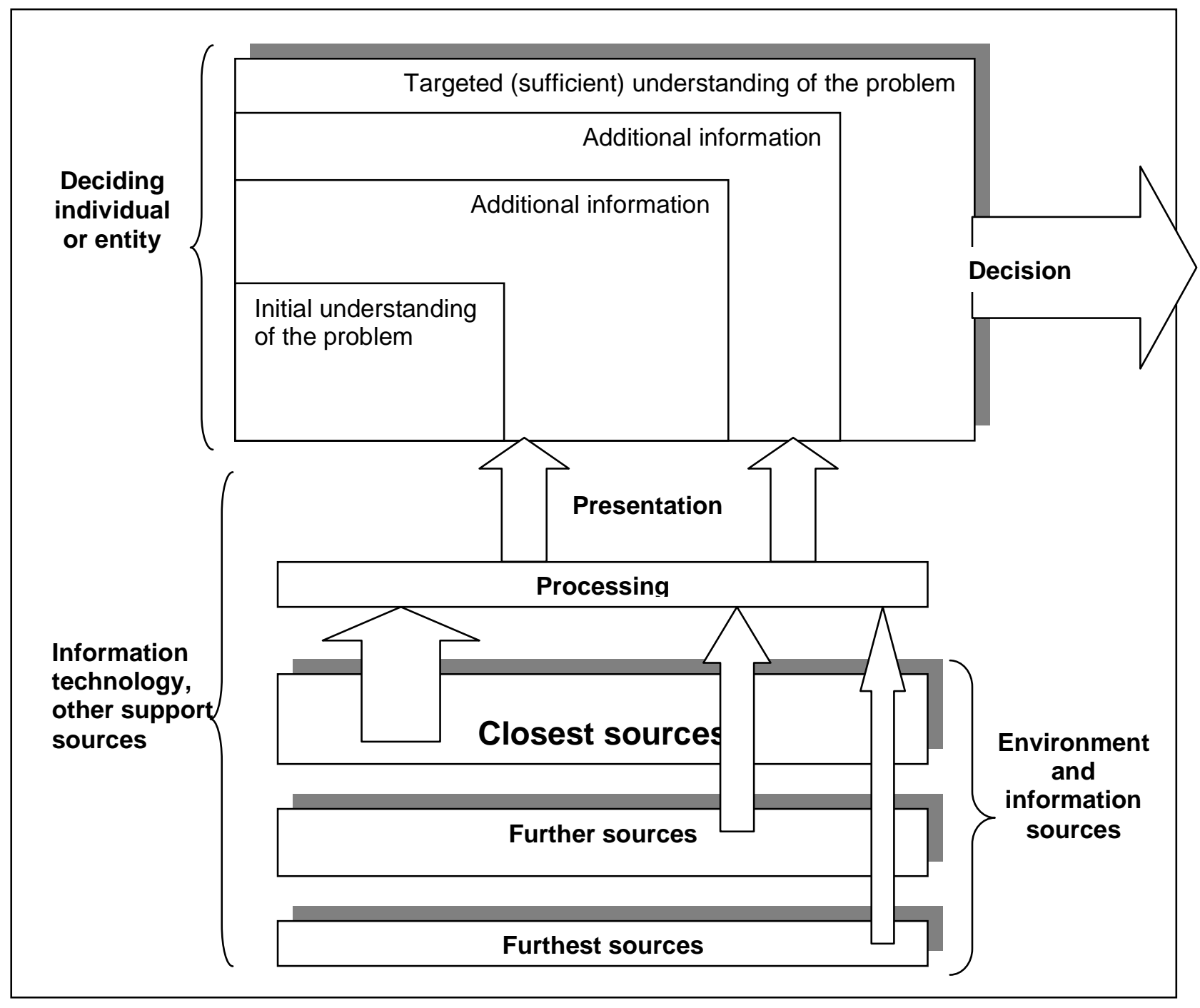

Figure 1. Generic structure of the decision development process 
According to (Wilson, 2000), information search functions include:

- starting: the means employed by the user to start initial search;

- chaining: following references in known material or "forward" chaining from known items through citation indexes;

- browsing: semi-directed or semi-structured searching;

- differentiating: using known differences in information sources as a way of filtering the amount of information obtained;

- monitoring: keeping up-to-date or current awareness searching;

- extracting: selectively identifying relevant material in an information source;

- verifying: checking the accuracy of information;

- ending: "tying up loose ends" through a final search.

As it has been already stated, a substantial amount of research and development in the DSS field has been directed towards the higher degree of automation of decision process. Meanwhile, based on earlier research, an assumption is made that users would welcome a "more with less" approach, meaning that IT should carry out the simple decision preparation tasks and present basic but important decision points, thus stimulating the decision maker's intellectual activities and role in decision development. The interview responses, presented further in the paper, support this point, though for statistically significant results, additional research is needed.

The structuring of information sources by their proximity is used in a sense that usually the closest and easiest to use information sources are utilized in the first place. The other important feature of information sources, considered in decision development process, is richness - ability to reduce uncertainty and ambiguity. The richness aspect of information sources has been investigated in a variety of sources (Saunders, \& Jones, 1990; Browne, 1993; Evans, \& Wurster, 2000). Substantial arguments have been provided to support the point that Web-based informing breaks the traditional reverse relationship between information richness and reach. Nevertheless, in the area of informing a decision maker, where interpersonal communication and "soft" information play one of the most significant roles, Web-style richness fails to provide such features of interpersonal communication as human presentation with intonations and body language, credibility, background of interpersonal relations.

It has been shown that a decision maker (person or entity) is willing to use all available information and knowledge to support decision development. The use of knowledge in decision making is an important topic in itself and, as such, goes well beyond the scope of this paper. The use of information is generally structured in such way that in the first place, the closest and most accessible information sources are used, gradually expanding the scope of information search until it becomes non-feasible. This can be explained by:

- low probability of valuable information in distant sources;

- growing cost and effort to obtain distant information.

The interviews have supported this point of view. 


\section{Findings and Assumptions}

The interview findings are presented below.

1. A possible extent of automation of the decision-making process. Although in theory all or nearly all phases of decision development can be automated, such functionality did not invoke much enthusiasm from the decision makers. The decision makers did not express the intent for their important decisions to be performed by a software "robot". Instead, the decision development functions most likely to be automated have been the routine information services functions - mostly information search and its reduction to comprehensible amounts. Automation and programming, by definition, addresses tasks that are repetitious in nature, whereas the problem situations are mostly different and unexpected; even for the same activity area, its context never stays constant. There are problems that have to be addressed with highlevel modelling tools, automating complex processing structures; in these cases, an issue of trust in modelling results comes up, especially in cases including some form of forecasting.

2. The part of the decision development process that IT should cover. As in the point \#1, the preference is for the simple part of the functionality spectrum, mostly for access to assorted information sources. Although the assumption had been made on the search strategy that the most general information had to be accessed first, gradually getting down to more problem-specific information, the key issue here proved to be proximity of information sources and convenience of their use: "20 percent of accessible sources should provide 80 percent of required information”.

3. Common features of the "cognitive gaps" in addressing decision problems. No such common features have been indicated with the exception of information on competition or available forecasts for the problem area. Most often, general information on the problem area is already available at the beginning of the decision process, with the exception of rare cases of unstructured situations, and the existing cognitive gaps are rather situation-specific.

4. Preference between different types of support tools. If limited time, money or other resources force a choice between potential tools for a situation, the priority is given to access tools that allow to access required information sources.

5. Information that ideally should be available all the time. Again, because of low similarity of problem situations, only the most general types of information have been indicated - such as information on own situation (financial, technology, research and development), market situation (competitors, products, substitutes etc.), macro situation (inflation, growth rates). Apart from this, each problem situation invokes its own heuristics and experience.

6. Information groups to be monitored for early warning and prevention of problems. With the exception of monitoring the competition, no such groups have been specified. An important feature that has been specified here, regardless of information, is the ability to check the same information from separate and independent sources, in its turn calling for ability of accessing different sources on the same subject.

\section{The potentially stimulating points of support:}

- Variety of information sources;

- Information extracted from these sources is easily recordable and retrievable;

- Easy archiving and recall;

- Convenient information sorting mechanisms;

- Discussion points and input from participants - recorded and retrievable;

- Any combined presentation of development information ("idea board"); 
- Recording of rejected assumptions in case of need to look why they have been rejected.

Summing up, the main roles that decision makers would assign to information technology are access to information sources and ability to compress relevant information into consumable amounts. Not much of a model-based decision support has been detected, although if processing is to be used, the traditionally flexible tools - spreadsheets, queries - are most likely to be used. The users had shown preference for tools and techniques that:

- are simple,

- hold their efficiency over time in related situations,

- are oriented towards stimulation than automation,

- $\quad$ are more on the 'simple and reliable' part of the IT tools spectrum.

\section{Conclusions}

The users' preferences in using decision support tools and technologies seem to have shifted from a paradigm of DSS as an integrated system to a loose set of support tools, the most important among them being access to key information sources and simple processing instruments. The use of simple tools does not distract the attention of a decision maker or makers and does not force them to concentrate on the technology at the expense of the problem understanding. These basic tools consume little time and are easy to use, leaving more time for high-value managerial activities - creative problem analysis and decision development.

The use of simple support tools should have one more positive side effect. Simple tools are easy to use, and therefore decision arguments obtained with the help of such tools are easily checked - this should serve as prevention for "pre-programmed" decisions, where somebody might be presenting data selectively to defend a preferred alternative.

Another conclusion that should be drawn based on the findings is: like in the relatively similar areas of investigation - intelligence, scientific research, criminal investigation - the procedures of decision consideration and development should be recorded in detail, whenever possible. This should be not done in the style of 'accumulating best practices', as proposed by the knowledge management researchers, but rather accumulating all practices, together with their evaluations, meaning wrong alternatives and bad decisions have to be documented as well. This information on all decision development practices should be structured and easily usable.

The statements presented in this paper are more of assumption type, as the number of the interviews used as a basis for this paper is quite low. The goals for the research work in this direction in the nearest future would be to widen the circle of empiric information sources to gain statistical significance for support or rejection of these statements.

\section{References}

Andersen, J.A. (2000). Intuition in managers: Are intuitive managers more effective? Journal of Managerial Psychology, 15, 1, 46-67.

Basi, R. (1998). Administrative decision making: a contextual analysis. Management Decision, 36/4, 232-240.

Bennett, R.H. (1998). The importance of tacit knowledge in strategic deliberations and decisions. Management Decision, 36/9, 589-597.

Browne, M. (1993). Organizational Decision Making and Information. Norwood, NJ: ABLEX Publishing Co. 
Choo, Ch.W. (1997). The Knowing Organization: How Organizations Use Information To Construct Meaning, Create Knowledge, and Make Decisions. Oxford University Press. Retrieved December 1, 1998 from the World Wide Web: http://www.fis.utoronto.ca/people/faculty/choo/FIS/KO/KO.htmi

Davenport, Th. (1997). Storming the Ivory Tower. CIO Magazine, April 15, 1997. Retrieved June 12, 1998 from the World Wide Web: nttp://www.cio.com/archive/041597 think_content.htmi

Evans, Ph., \& Wurster, Th. (2000). Blown to bits: how the new economics of information transforms strategy. Boston, MA: HBS Press.

Galliers, R.D., \& Newell, S.M. (2000). Challenges of Information Technology Management in the $21^{\text {st }}$ Century: 2000 Information Resources Management Association International Conference, Anchorage, Alaska, USA, 1144-1145.

Hutchinson, B. (2000). Human centred computing: Interests, issues, expectations and results. Challenges of Information Technology Management in the $21^{\text {st }}$ Century: 2000 Information Resources Management Association International Conference, Anchorage, Alaska, USA, 1217-1218.

Ivanov, K. (1997). Computer-supported human science or humanistic computing science? University of Umea, Sweden. Retrieved February 9, 2001 from the World Wide Web: http://WwW.1nformat1K.umu.se/ K1vanov/page4.htm!

Malhotra, Y. (2000). From Information Management to Knowledge Management: Beyond the 'Hi-Tech Hidebound' Systems. In K. Srikantaiah \& M.E.D. Koenig (Eds.), Knowledge Management for the Information Professional. Medford, N.J.: Information Today Inc., 37-61.

Raggad, B.G. (1997). Decision support system: use IT or skip IT. Industrial Management \& Data Systems, 97/2, 43-50.

Saunders, C., \& Jones, J.W. (1990). Temporal Sequences in Information Acquisition for Decision Making: A Focus on Source and Medium. Academy of Management Review, 15, 1, 29-46.

Sauter, V. (1999). Intuitive Decision Making. Communications of the ACM, 42, 6, 109-116.

Skyrius, R. (2000). Business decision making, managerial learning and information technology. 2001 Informing Science Conference, Krakow, Poland. Retrieved February 16, 2002 from the World Wide Web: http:/lecommerce.lebow.drexel.edu/eli/pdf/SkyriusEBKBusin.pdf

Wilson, T.D. (2000), Human Information Behavior. Informing Science, 3, 2, 49-55.

Workshop on Information Technology Research for Crisis management. (1999). Washington, DC: National Academy Press. 